\title{
Effect of high-flow nasal cannula oxygen therapy in adults with acute hypoxemic respiratory failure: a meta-analysis of randomized controlled trials
}

\author{
Xiaofeng Ou MD PhD, Yusi Hua MD MSc, Jin Liu MD PhD, Cansheng Gong MD PhD, Wenling Zhao MD MSc
}

- Cite as: CMAJ 2017 February 21;189:E260-7. doi: 10.1503/cmaj.160570

See also www.cmaj.ca/lookup/doi/10.1503/cmaj.161303

\begin{abstract}
BACKGROUND: Conflicting recommendations exist on whether high-flow nasal cannula (HFNC) oxygen therapy should be administered to adult patients in critical care with acute hypoxemic respiratory failure. We performed a meta-analysis of randomized controlled trials (RCTs) to evaluate its effect on intubation rates.
\end{abstract}

METHODS: We searched electronic databases from inception to April 2016. We included RCTs that compared HFNC oxygen therapy with usual care (conventional oxygen therapy or noninvasive ventilation) in adults with acute hypoxemic respiratory failure. Because of the different methodologies and variation in clinical outcomes, we conducted 2 subgroup analyses according to oxygen therapy used and disease severity. We pooled data using random-effects models. The primary outcome was the proportion of patients who required endotracheal intubation.

RESULTS: We included 6 RCTs $(n=1892)$. Compared with conventional oxygen therapy, HFNC oxygen therapy was associated with a lower intubation rate (risk ratio [RR] $0.60,95 \%$ confidence interval $[\mathrm{Cl}] 0.38$ to $0.94 ; R=49 \%$ ). We found no significant difference in the rate between HFNC oxygen therapy and noninvasive ventilation (RR
$0.86,95 \% \mathrm{Cl} 0.68$ to $\left.1.09 ; P^{2}=2 \%\right)$. In the subgroup analysis by disease severity, no significant differences were found in the intubation rate between HFNC oxygen therapy and either conventional oxygen therapy or noninvasive ventilation (interaction $p=0.3$ and 0.4 , respectively).

INTERPRETATION: The intubation rate with HFNC oxygen therapy was lower than the rate with conventional oxygen therapy and similar to the rate with noninvasive ventilation among patients with acute hypoxemic respiratory failure. Larger, high-quality RCTs are needed to confirm these findings.
A cute respiratory failure is common in the intensive care unit (ICU), often requiring endotracheal intubation. For patients with acute hypoxemic respiratory failure who require intubation, mechanical ventilation is usually needed, which is associated with high mortality. ${ }^{1}$ Preventing acute respiratory failure and endotracheal intubation is therefore important. Oxygen therapy is used to correct hypoxemia and to alleviate breathlessness and removal of the endotracheal tube, ${ }^{2}$ but knowing which form of oxygen therapy to choose is unclear.

Noninvasive ventilation is often used to avoid reintubation and improve outcomes. ${ }^{3,4}$ However, results of studies of its effectiveness in the prevention of intubation and improvement of outcomes of patients with acute respiratory failure have been conflicting. ${ }^{5-12}$ Several observational studies showed that noninvasive ventilation was unsuccessful in as many as half of patients with acute respiratory failure ${ }^{8-10}$ and was often associated with high mortality. ${ }^{11,12}$ In addition, it is not convenient to implement because it requires substantial resources and may cause patient discomfort. 3,13,14

High-flow nasal cannula (HFNC) oxygen therapy is increasingly being used for noninvasive respiratory support in ICUs. It delivers humidified oxygen at a flow rate of up to $60 \mathrm{~L} / \mathrm{min}$ through a nasal cannula. By delivering oxygen at high flow rates, this form of oxygen therapy not only provides a constant fraction of inspired oxygen $\left(\mathrm{FIO}_{2}\right)$, which can be adjusted by changing the fraction of oxygen in the driving gas, ${ }^{15}$ it also increases end-expiratory lung volume, decreases physiologic dead space and reduces the patient's breathing effort. ${ }^{16,17}$

Although some studies have found that HFNC oxygen therapy improves oxygenation, ${ }^{18}$ survival, ${ }^{19}$ tolerance and comfort, ${ }^{20,21}$ and eases drainage of respiratory secretions, ${ }^{22}$ its effect on intubation rates remains unclear. A systematic review showed that it may improve oxygenation compared with conventional oxygen therapy. ${ }^{23}$ 
However, its effect on intubation rates was not studied, and some limitations, such as small samples, poor-quality trials and the narrative synthesis of data, were prone to generate bias and heterogeneity. ${ }^{24}$

We conducted a meta-analysis of randomized controlled trials (RCTs) to evaluate the effect of HFNC oxygen therapy on intubation rates among adults in ICU with acute hypoxemic respiratory failure.

\section{Methods}

We conducted this study according to the methods in the Cochrane Handbook for Systematic Reviews of Interventions..$^{25}$ We report the findings according to the Preferred Reporting Items for Systematic Reviews and Meta-Analyses (PRISMA) statement. ${ }^{26}$

\section{Literature search}

We searched MEDLINE, Embase and the Cochrane Central Register of Controlled Trials from inception to Apr. 18, 2016; the Chinese Biomedical Literature Database from 1978 to April 2016; and the Wanfang Data database from 1990 to 2016. Language was restricted to English and Chinese. We also searched the ClinicalTrials.gov registry in April 2016 to identify additional clinical trials. Details of the search strategy are provided in Appendix 1 (available at www.cmaj.ca/ lookup/suppl/doi:10.1503/cmaj.160570/-/DC1).

\section{Study selection}

After the screening of titles, we evaluated abstracts for relevance and identified them as included, excluded or requiring further assessment. We considered RCTs eligible if they compared HFNC oxygen therapy with other oxygen therapies and included adults (age > 16 yr) in ICUs with acute hypoxemic respiratory failure (ratio of partial pressure of arterial oxygen to inspired fraction of oxygen $\left[\mathrm{PaO}_{2}: \mathrm{FlO}_{2}\right] \leq 300 \mathrm{~mm} \mathrm{Hg}$ ).

Oxygen therapies included HFNC oxygen therapy, conventional oxygen therapy and noninvasive ventilation. High-flow nasal cannula oxygen therapy was described as the delivery of oxygen through a heated humidifier and nasal cannula at a flow rate greater than $15 \mathrm{~L} / \mathrm{min}$. Conventional oxygen therapy involved oxygen delivery by nasal cannula or mask. Noninvasive ventilation involved the use of a face mask connected to an ICU ventilator, with pressure support applied in a noninvasive ventilation mode.

We excluded studies published in narrative reviews, commentaries and editorials. We also excluded trials whose participants were volunteers, immunocompromised patients or patients with advanced cancer or trauma-related hypoxemia.

\section{Data extraction and quality assessment}

The primary outcome measure was the proportion of patients who required endotracheal intubation. The secondary outcome measures were physiologic outcomes (oxygenation [as measured by $\mathrm{PaO}_{2}: \mathrm{FIO}_{2}$ ratio], partial pressure of carbon dioxide $\left[\mathrm{PaCO}_{2}\right]$, arterial $\mathrm{pH}$ and respiratory rate), mortality in ICU, length of ICU stay and ventilator-induced lung injury (e.g., pneumothorax).

Two of us (X.O. and Y.H.) used a standardized spreadsheet to independently extract data on study eligibility, methods, methodologic quality and outcomes. Disagreements were resolved by consensus after contact with the trial authors. We assessed the risk of bias for each trial using the Cochrane risk-of-bias tool. ${ }^{27}$ We assigned a value of low, unclear or high risk of bias to the following domains: random sequence generation, allocation concealment, blinding of participants and personnel, blinding of outcome assessment, incomplete outcome data, selective reporting and other bias. After extracting data on methods of randomization, allocation concealment ${ }^{28}$ and blinding of outcome assessors, ${ }^{29}$ we extracted the following study features: first author, publication year, country, number of participants, protocols of oxygen therapies, and the primary and secondary outcomes.

\section{Data synthesis}

We pooled data using random-effects models. For binary outcomes, we calculated risk ratios (RRs) with 95\% confidence intervals (Cls). For continuous outcomes, we calculated mean differences (MDs) with $95 \% \mathrm{Cls}$. We considered a $p$ value of less than 0.05 to be statistically significant.

We assessed heterogeneity using the Mantel-Haenszel $\chi^{2}$ test and the $R^{2}$ statistic. We considered heterogeneity to be substantial if the $R^{2}$ value was $50 \%$ or greater or the $p$ value was 0.1 or less. ${ }^{30,31}$ We did not assess publication bias because of the low power associated with the low number of included studies.

We conducted 2 subgroup analyses. First, because of the quite different methodologies and clinical features of each oxygen therapy, we analyzed separately the trials that compared HFNC oxygen therapy with conventional oxygen therapy and those that compared HFNC with noninvasive ventilation. Second, because the

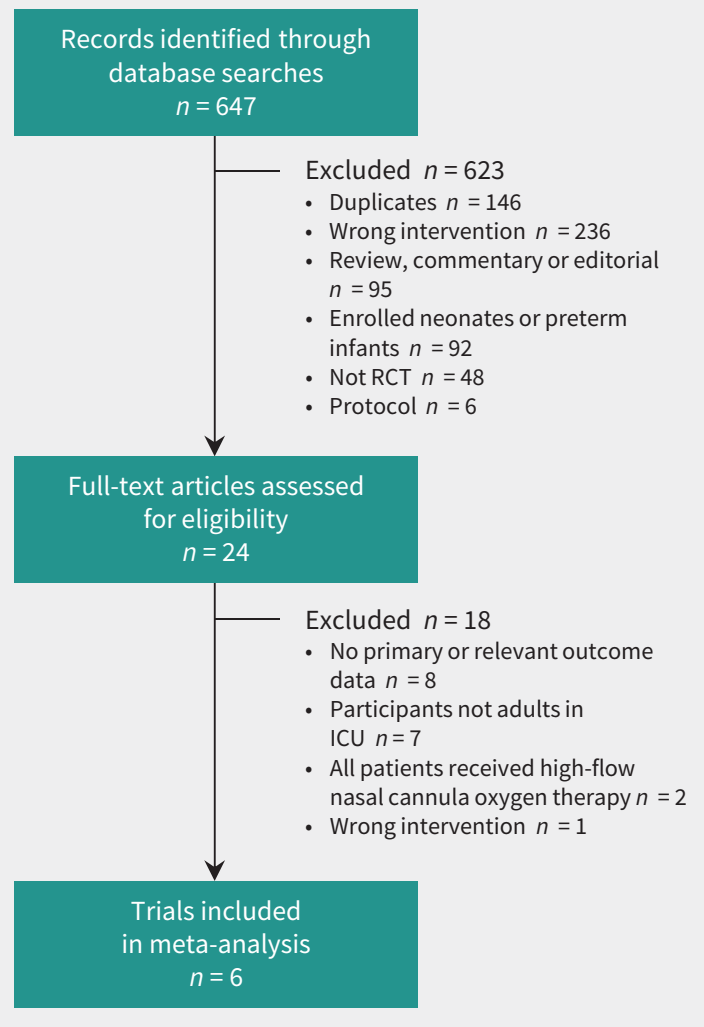

Figure 1: Selection of randomized controlled trials (RCTs) for the meta-analysis. 
participants' disease severity may have affected study outcomes, we conducted a subgroup analysis according to disease severity based on patients' Acute Physiologic Assessment and Chronic Health Evaluation (APACHE) II score $(<15$ v. $\geq 15)$ and Simplified Acute Physiology Score (SAPS II) $(<30$ v. $\geq 30)$. We described patients' disease severity as low risk, unknown risk and high risk.

To assess the robustness of the results of our meta-analysis, we conducted sensitivity analyses using alternative effect measures (odds ratios $v$. RRs) and statistical models regarding heterogeneity (random v. fixed effects).

We performed all statistical analyses using Review Manager software (RevMan version 5.3; Cochrane Collaboration).

\section{Results}

\section{Search results and study characteristics}

We identified 647 citations through the literature search. After screening the titles and abstracts, we reviewed 24 records in full; 6 RCTs $(n=1892)^{19,21,32-35}$ met our inclusion criteria and were included in the meta-analysis (Figure 1). (Details of the 18 excluded trials are shown in Appendix 2, available at www.cmaj.ca/lookup/ suppl/doi:10.1503/cmaj.160570/-/DC1.)

The characteristics of the 6 included trials are listed in Table 1. One of the trials compared HFNC oxygen therapy with both conventional oxygen therapy and noninvasive ventilation, ${ }^{19} 3$ trials compared it with conventional oxygen therapy only,,$^{21,33,34}$ and 2 trials compared it with noninvasive ventilation only. ${ }^{32,35}$ The primary outcome measure of 3 trials ${ }^{19,32,33}$ was the intubation rate, consistent with our study. Two trials considered oxygenation $\left(\mathrm{PaO}_{2}: \mathrm{FIO}_{2}\right.$ ratio) as their primary outcome..$^{21,35}$ One trial was published as an abstract only, and its primary outcome was lung aeration variation. ${ }^{34}$

Five trials were judged to have high methodologic quality and a low risk of bias, ${ }^{19,21,32,33,35}$ with adequate randomized sequences, concealed allocation and analyzed clinical outcomes for patients by assigned group (Appendix 3, available at www.cmaj.ca/lookup/ suppl/doi:10.1503/cmaj.160570/-/DC1). The methodologic quality and risk of bias of the trial published as an abstract was assessed to be unclear because insufficient data were available after contacting the study investigators. ${ }^{34}$ Two trials reported that $2(4.7 \%)^{35}$ and $3(1.0 \%)^{19}$ patients, respectively, were withdrawn because

\section{Table 1: Characteristics of randomized controlled trials included in the meta-analysis}

\begin{tabular}{|c|c|c|c|c|c|c|c|}
\hline \multirow[b]{2}{*}{ Trial } & \multirow[b]{2}{*}{ Setting } & \multirow{2}{*}{$\begin{array}{l}\text { No. of } \\
\text { patients } \\
\text { (\% male) }\end{array}$} & \multirow{2}{*}{$\begin{array}{l}\text { Age, yr, } \\
\text { mean }\end{array}$} & \multirow{2}{*}{$\begin{array}{c}\text { Disease } \\
\text { severity scores, } \\
\text { mean }\end{array}$} & \multirow[b]{2}{*}{ Enrolment criteria } & \multicolumn{2}{|c|}{ Oxygen therapy protocol, mean \pm SD } \\
\hline & & & & & & HFNC group & Control group \\
\hline $\begin{array}{l}\text { Frat et al., } \\
2015^{19}\end{array}$ & $\begin{array}{l}23 \text { ICUs } \\
\text { in France } \\
\text { and } \\
\text { Belgium }\end{array}$ & $\begin{array}{c}310 \\
(68.4)\end{array}$ & $\begin{array}{l}\text { - HFNC: } 61 \\
\text { - Conventional } \\
\text { oxygen: } 59 \\
\text { - NIV: } 61\end{array}$ & $\begin{array}{l}\text { SAPS II: } \\
\text { - HFNC: } 25 \\
\text { - Conventional } \\
\text { oxygen: } 24 \\
\text { - NIV: } 27\end{array}$ & $\begin{array}{l}\mathrm{PaO}_{2}: \mathrm{FlO}_{2} \text { ratio } \\
\leq 300 \mathrm{~mm} \mathrm{Hg} ; \mathrm{PaCO}_{2} \\
\leq 45 \mathrm{~mm} \mathrm{Hg} \\
\text { respiratory rate } \\
\geq 25 \text { beats/min; } \\
\text { no history of chronic } \\
\text { respiratory failure }\end{array}$ & $\begin{array}{l}\text { - Gas flow rate: } \\
48 \pm 11 \mathrm{~L} / \mathrm{min} \\
\text { - } \mathrm{FIO}_{2}: 0.82 \pm 0.21\end{array}$ & $\begin{array}{l}\text { Group 1: Non-rebreather mask } \\
\text { - Gas flow rate: } 13 \pm 5 \mathrm{~L} / \mathrm{min} \\
\text { - } \mathrm{FIO}_{2}: 0.82 \pm 0.21 \\
\text { Group 2: NIV } \\
\text {-PS: } 8 \pm 3 \mathrm{~cm} \mathrm{H}_{2} \mathrm{O} \\
\text {-PEEP: } 5 \pm 1 \mathrm{~cm} \mathrm{H}_{2} \mathrm{O} \\
\text { - FIO }: 0.67 \pm 0.24 \\
\text { - VT: } 9.2 \pm 3.0 \mathrm{~mL} / \mathrm{kg}\end{array}$ \\
\hline $\begin{array}{l}\text { Hernandez } \\
\text { et al., } 2016^{33}\end{array}$ & $\begin{array}{l}7 \text { ICUs in } \\
\text { Spain }\end{array}$ & $527(62.0)$ & $\begin{array}{l}\text { - HFNC: } 51 \\
\text { - Conventional } \\
\text { oxygen: } 52\end{array}$ & $\begin{array}{l}\text { APACHE II: } \\
\text { - HFNC: } 14 \\
\text { - Conventional } \\
\text { oxygen: } 13\end{array}$ & $\begin{array}{l}\mathrm{PaO}_{2}: \mathrm{FIO}_{2} \text { ratio } \\
>150 \mathrm{~mm} \mathrm{Hg} \\
\mathrm{PaCO}_{2} \leq 45 \mathrm{~mm} \mathrm{Hg} ; \\
\mathrm{pH}>7.35\end{array}$ & $\begin{array}{l}\text { - Gas flow rate: } \\
30.9 \pm 7.6 \mathrm{~L} / \mathrm{min} \\
\text { - } \mathrm{FIO}_{2}: 0.32 \pm 0.08\end{array}$ & $\begin{array}{l}\text { Nasal cannula or non- } \\
\text { rebreather mask } \\
\text { - Gas flow rate adjusted to } \\
\text { maintain } \mathrm{SpO}_{2} \text { at } \geq 92 \mathrm{~mm} \mathrm{Hg} \\
\text { - } \mathrm{FIO}_{2}: 0.4 \pm 0.09\end{array}$ \\
\hline $\begin{array}{l}\text { Maggiore } \\
\text { et al., } \\
2014^{21}\end{array}$ & $\begin{array}{l}2 \text { ICUs in } \\
\text { Italy }\end{array}$ & $105(64.8)$ & $\begin{array}{l}\cdot \text { HFNC: } 65 \\
\text { - Conventional } \\
\text { oxygen: } 64\end{array}$ & $\begin{array}{l}\text { SAPS II: } \\
\text { - HFNC: } 43 \\
\text { - Conventional } \\
\text { oxygen: } 44\end{array}$ & $\begin{array}{l}\mathrm{PaO}_{2}: \mathrm{FlO}_{2} \text { ratio } \\
\leq 300 \mathrm{~mm} \mathrm{Hg} \\
\mathrm{PaCO}_{2} \geq 45 \mathrm{~mm} \mathrm{Hg} \\
\text { respiratory rate } \\
\geq 25 \text { beats/min }\end{array}$ & $\begin{array}{l}\text { - Gas flow rate: } \\
50 \mathrm{~L} / \mathrm{min} \\
\text { - } \mathrm{FIO}_{2} \text { adjusted to } \\
\text { maintain } \mathrm{Spo}_{2} \text { at } \\
\text { 92-98 } \mathrm{mm} \mathrm{Hg}\end{array}$ & $\begin{array}{l}\text { Venturi mask } \\
\text { - Gas flow rate and } \mathrm{FiO}_{2} \\
\text { adjusted to maintain } \mathrm{SpO}_{2} \\
\text { at } 92-98 \mathrm{~mm} \mathrm{Hg}\end{array}$ \\
\hline $\begin{array}{l}\text { Perbet et al., } \\
2014^{34 \star}\end{array}$ & $\begin{array}{l}4 \text { ICUs in } \\
\text { France }\end{array}$ & 80 & NA & NA & NA & NA & Conventional oxygen therapy \\
\hline $\begin{array}{l}\text { Simon et } \\
\text { al., } 2014^{35}\end{array}$ & $\begin{array}{l}1 \mathrm{ICU} \text { in } \\
\text { Germany }\end{array}$ & $\begin{array}{c}40 \\
(60.0)\end{array}$ & $\begin{array}{l}\text { - HFNC: } 64 \\
\text { - NIV: } 68\end{array}$ & $\begin{array}{l}\text { SAPS II: } \\
\text { - HFNC: } 43 \\
\text { - NIV: } 46\end{array}$ & $\begin{array}{l}\mathrm{PaO}_{2}: \mathrm{FIO}_{2} \text { ratio } \\
<300 \mathrm{~mm} \mathrm{Hg}\end{array}$ & $\begin{array}{l}\text { - Gas flow rate: } \\
50 \mathrm{~L} / \mathrm{min} \\
\text { - } \mathrm{FIO}_{2} \text { adjusted to } \\
\text { maintain } \mathrm{SaO}_{2} \text { at } \\
>90 \mathrm{~mm} \mathrm{Hg}\end{array}$ & $\begin{array}{l}\text { NIV } \\
\text { - PEEP: 3-10 } \mathrm{cm} \mathrm{H}_{2} \mathrm{O} \\
\text { - Inspiratory pressure: } \\
\text { 15-20 } \mathrm{cm} \mathrm{H}_{2} \mathrm{O}\end{array}$ \\
\hline $\begin{array}{l}\text { Stephan et } \\
\text { al., } 2015^{32}\end{array}$ & $\begin{array}{l}6 \text { ICUs in } \\
\text { France }\end{array}$ & $830(66.4)$ & $\begin{array}{l}\text { - HFNC: } 64 \\
\text { - NIV: } 64\end{array}$ & $\begin{array}{l}\text { SAPS II: } \\
\text { - HFNC: } 29 \\
\text { - NIV: } 29\end{array}$ & $\begin{array}{l}\mathrm{PaO}_{2}: \mathrm{FlO}_{2} \text { ratio } \\
\leq 300 \mathrm{~mm} \mathrm{Hg} \\
\text { respiratory rate } \\
\geq 25 \text { beats } / \mathrm{min}\end{array}$ & $\begin{array}{l}\text { - Gas flow rate: } \\
50 \mathrm{~L} / \mathrm{min} \\
\text { - } \mathrm{FlO}_{2} \text { adjusted to } \\
\text { maintain } \mathrm{SpO}_{2} \text { at } \\
\text { 92-98 } \mathrm{mm} \mathrm{Hg}^{-}\end{array}$ & $\begin{array}{l}\text { BiPAP } \\
\text { - PEEP: } 4 \mathrm{~cm} \mathrm{H} \mathrm{H}_{2} \\
\text { - PS: } 8 \mathrm{~cm} \mathrm{H} \mathrm{H}_{2} \mathrm{O} \text { (initial) } \\
\text { - } \mathrm{FIO}_{2}: 0.5 \text { (initial) }\end{array}$ \\
\hline
\end{tabular}

Note: APACHE II = Acute Physiology and Chronic Health Evaluation II score (range 0 to 71 points, with higher scores indicating more severe disease), BiPAP = bilevel positive airway pressure, $\mathrm{HFNC}=$ high-flow nasal cannula oxygen therapy, $\mathrm{ICU}=$ intensive care unit, $\mathrm{NA}=$ not available, $\mathrm{NIV}=$ noninvasive ventilation, $\mathrm{PaCO}_{2}=$ partial pressure of arterial carbon dioxide, $\mathrm{PaO} \mathrm{O}_{2}: \mathrm{FIO}_{2}=$ ratio

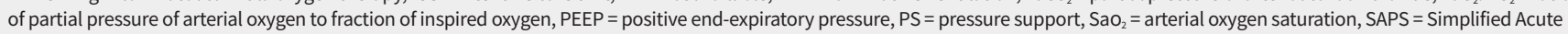

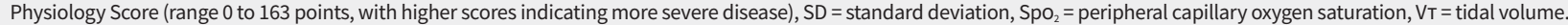

${ }^{*}$ Conference abstract; details about the trial and some outcomes were not available after author contact. 
consent was declined. None of the trials were double-blinded because it was too difficult to have patients and clinicians unaware of the protocol; however, the primary outcome was not likely to be influenced.

\section{Effect on intubation rate}

All 6 RCTs reported data on the proportion of patients requiring endotracheal intubation (Table 2). Overall, $19.1 \%$ of patients required intubation. The subgroup analyses by type of oxygen therapy showed no statistically significant difference between subgroups (interaction $p=0.2$ ). Within subgroups, the intubation rate was significantly lower with HFNC oxygen therapy than with conventional oxygen therapy (RR $0.60,95 \% \mathrm{Cl} 0.38$ to $0.94 ; P^{2}=49 \%$ ). No significant difference was found between HFNC oxygen therapy and noninvasive ventilation ( $\mathrm{RR} 0.86,95 \% \mathrm{Cl} 0.68$ to $1.09 ; P^{2}=2 \%$ ) (Figure 2).

In the subgroup analyses by disease severity, we described patients' disease severity as low risk in 3 trials, ${ }^{19,32,33}$ unknown risk in 1 trial ${ }^{34}$ and high risk in 2 trials. ${ }^{21,35}$ We found no significant difference between subgroups (interaction $p=0.3$ for comparison of HFNC $v$. conventional oxygen therapy, and 0.4 for comparison of HFNC $v$. noninvasive ventilation). Within subgroups, we found no significant difference in intubation rates between HFNC and conventional oxygen therapy (low-risk patients: RR $0.59,95 \% \mathrm{Cl} 0.30$ to 0.19 ; high-risk patients: RR $0.37,95 \% \mathrm{Cl} 0.16$ to 0.87 ) or between HFNC and noninvasive ventilation (low-risk patients: RR $0.89,95 \% \mathrm{Cl} 0.66$ to 1.20 ; high-risk patients: RR 0.69, 95\% Cl 0.39 to 1.24 ) (Figure 3).

\section{Effect on secondary outcome measures}

The effect of HFNC oxygen therapy on physiologic outcomes is summarized in Table 3.

Data on $\mathrm{PaO}_{2}: \mathrm{FlO}_{2}$ ratios and $\mathrm{PaCO}_{2}$ levels were available from 5 trials $(n=1812)$. No significant difference in either measure was found between HFNC oxygen therapy and conventional oxygen therapy $\left(\mathrm{PaO}_{2}: \mathrm{FIO}_{2}\right.$ ratio: $\mathrm{MD} 4.72 \mathrm{~mm} \mathrm{Hg}, 95 \% \mathrm{Cl}-28.90$ to $38.33 \mathrm{~mm} \mathrm{Hg}, I^{2}=90 \%$; $\mathrm{PaCO}_{2}$ level: MD $-0.40 \mathrm{~mm} \mathrm{Hg}, 95 \% \mathrm{Cl}-2.54$ to $1.74 \mathrm{~mm} \mathrm{Hg}, I^{2}=71 \%$ ). Subgroup analyses by disease severity showed significant differences in both $\mathrm{PaO}_{2}: \mathrm{FIO}_{2}$ ratio and $\mathrm{PaCO}_{2}$ level (interaction $p<0.001$ and 0.01 , respectively).

When we compared HFNC oxygen therapy and noninvasive ventilation, we found a significantly lower $\mathrm{PaO}_{2}: \mathrm{FIO}_{2}$ ratio in the HFNC group (MD $-53.84,95 \% \mathrm{Cl}-71.43$ to $-36.24 \mathrm{~mm} \mathrm{Hg}$; ${ }^{2}=44 \%$ ) but no significant difference in the $\mathrm{PaCO}_{2}$ level (MD $-0.53,95 \% \mathrm{Cl}$ -2.34 to $1.28 ; P^{2}=62 \%$ ). Subgroup analyses by disease severity showed no significant differences in $\mathrm{PaO}_{2}: \mathrm{FIO}_{2}$ ratio or $\mathrm{PaCO}_{2}$ level (interaction $p=0.07$ and 0.3 , respectively) (Table 3).

When we analyzed data on arterial pH ( 3 trials; $n=1667$ lowrisk patients), we found no significant difference between patient groups by type of oxygen therapy (Table 3). Respiratory rate ( 3 trials; $n=1245$ ) was significantly lower in the HFNC group than in either the conventional oxygen group (MD -3.68 breaths/ $\min , 95 \% \mathrm{Cl}-6.81$ to $\left.-0.55 ; P^{2}=83 \%\right)$ or the noninvasive ventilation group (MD -1.13 breaths $/ \mathrm{min}, 95 \% \mathrm{Cl}-2.01$ to $-0.25 ; I^{2}=8 \%$ ) (Table 3).

\begin{tabular}{|c|c|c|c|}
\hline Trial & $\begin{array}{c}\text { No. }(\%) \\
\text { of patients }\end{array}$ & $\begin{array}{l}\text { Intubation required, } \\
\text { no. }(\%) \text { of patients }\end{array}$ & $p$ value \\
\hline Frat et al., $2015^{19}$ & & & 0.2 \\
\hline HFNC & 106 & $40(37.7)$ & \\
\hline Conventional oxygen therapy & 94 & $44(46.8)$ & \\
\hline NIV & 110 & $55(50.0)$ & \\
\hline Hernandez et al., $2016^{33}$ & & & 0.004 \\
\hline HFNC & 264 & $13(4.9)$ & \\
\hline Conventional oxygen therapy & 263 & $32(12.2)$ & \\
\hline Maggiore et al., 2014²1 & & & 0.01 \\
\hline HFNC & 53 & $6(11.3)$ & \\
\hline Conventional oxygen therapy & 52 & $16(30.8)$ & \\
\hline Perbet et al., $2014^{34}$ & & & 0.8 \\
\hline HFNC & 40 & $9(22.5)$ & \\
\hline Conventional oxygen therapy & 40 & $10(25.0)$ & \\
\hline Simon et al., $2014^{35}$ & & & 0.2 \\
\hline HFNC & 20 & $9(45.0)$ & \\
\hline NIV & 20 & $13(65.0)$ & \\
\hline Stephan et al., $2015^{32}$ & & & $>0.9$ \\
\hline HFNC & 414 & $57(13.8)$ & \\
\hline NIV & 416 & $58(13.9)$ & \\
\hline
\end{tabular}


Five trials ( $n=1852)$ described data on ICU mortality, and 4 ( $n=$ 1772) reported information on length of ICU stay. There were 52 (5.9\%) deaths in the HFNC group, $30(6.7 \%)$ in the conventional oxygen therapy group and $50(9.5 \%)$ in the noninvasive ventilation group. Pooled analyses of the results showed no difference in these outcome measures by type of oxygen therapy or by disease severity $(p>0.05)$ (Table 3$)$.

Two trials mentioned the incidence of ventilator-induced lung injury. ${ }^{19,32}$ One of them found that noninvasive ventilation was associated with an increased incidence of ventilator-induced lung injury because of increasing tidal volumes. ${ }^{19}$ In the other trial, ${ }^{32}$ pneumothorax developed in $8(1.9 \%)$ patients in the HFNC group and $7(1.7 \%)$ in the noninvasive ventilation group; the difference was not significant (RR 1.15, 95\% Cl 0.42 to 3.14 ) (Table 3).

\section{Sensitivity analysis}

When we repeated our meta-analyses using alternative effect measures (odds ratios v. risk ratios) and statistical models regarding heterogeneity (random v. fixed effects), the results were statistically similar to those from the primary analyses (Appendices 4-9, available at www.cmaj.ca/lookup/suppl/doi:10.1503/cmaj $.160570 /-/ D C 1)$.

\section{Interpretation}

Our study showed that the proportion of patients with acute hypoxemic respiratory failure who required endotracheal intubation was lower among those who received HFNC oxygen therapy than among those given conventional oxygen therapy. The intubation rate did not differ significantly between HFNC oxygen therapy and noninvasive ventilation. In the subgroup analyses by disease severity, high-risk patients had a lower intubation rate with HFNC oxygen therapy than with conventional oxygen therapy. However, this result was based on only 1 trial with small samples. ${ }^{21}$ Larger trials are needed to confirm the effects of HFNC in this patient group.

The improvement in the intubation rate with HFNC oxygen therapy was consistent with the results of some observational studies. ${ }^{36,37}$ Our results showed that the intubation rate with noninvasive ventilation was only $23 \%$, which was much lower than the reported range of $46 \%-54 \% .3,8,9,25$ This difference may have been because most $(76 \%)$ of the participants with low disease severity came from 1 trial, which reported an intubation rate of only $14 \% .{ }^{32}$

An improvement in the $\mathrm{PaO}_{2}: \mathrm{FIO}_{2}$ ratio was observed among patients receiving noninvasive ventilation compared with HFNC oxygen therapy, as has been reported previously. ${ }^{38}$ This result may have been due to the higher positive end-expiratory pressure or higher mean airway pressure being applied during noninvasive ventilation. ${ }^{39,40}$ We found no significant differences between HFNC oxygen therapy and the control groups in ICU mortality or length of ICU stay. This is perhaps because the rate of death in the lowrisk population in the study by Hernandez and colleagues, ${ }^{33}$ the second largest study included in our meta-analysis, was too low to drive these results in the entire group.

These oxygen therapies are not without risks. One trial indicated that noninvasive ventilation was associated with increased risk of ventilator-induced lung injury. ${ }^{19}$ Although no significant difference in the incidence of pneumothorax was found between HFNC oxygen therapy and noninvasive ventilation, the available data were limited, and these adverse events may occur more frequently with increasing tidal volumes.

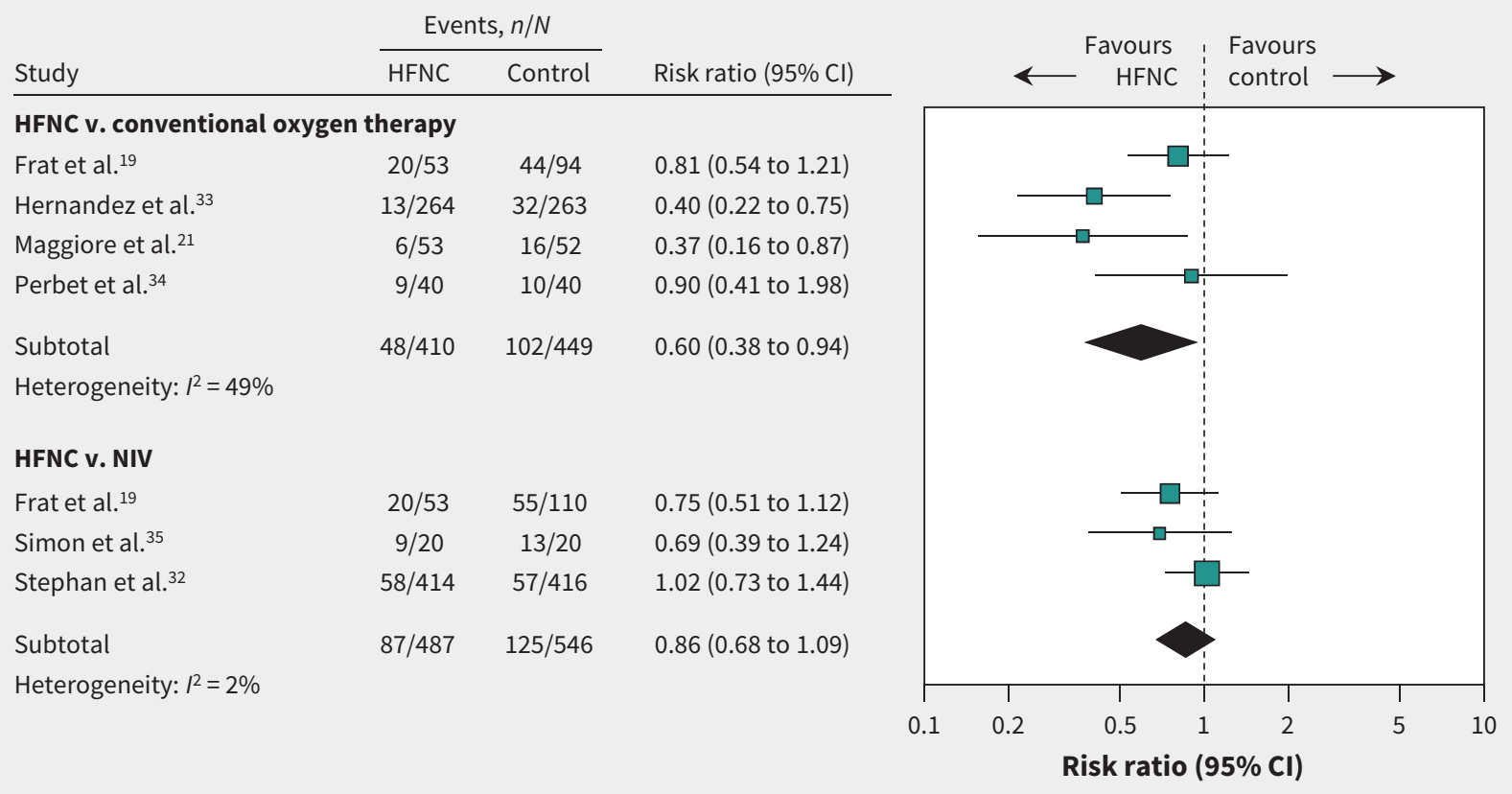

Figure 2: Subgroup analysis of intubation rate by type of oxygen therapy. A risk ratio of less than 1.0 indicates an effect in favour of HFNC oxygen therapy. Error bars represent $95 \%$ confidence intervals. $\mathrm{Cl}=$ confidence interval, $\mathrm{HFNC}=$ high-flow nasal cannula oxygen therapy, NIV = noninvasive ventilation . 


\section{Limitations}

Although we found high-quality evidence and used rigorous methodology, our study has several limitations. First, the included trials were diverse with respect to inclusion criteria, disease severity and use of oxygen therapy protocols. Three trials included 1462 patients (77.3\% of total study population) and were conducted in the setting of post-extubation respiratory failure, ${ }^{21,32,33}$ which may generate potential bias. Four trials included 1747 low-risk patients (92.3\% of total study population), who tended to have better outcomes and lower intubation rates than high-risk patients. ${ }^{19,32-34}$ However, we strengthened the stability and accuracy of our meta-analysis by using strict trial identification, data extraction and subgroup analysis.
Second, our meta-analysis was based on relatively few trials and 2 of them had small samples $(<100) \cdot{ }^{34,35}$ This may have underestimated heterogeneity and reduced precision. In addition, we restricted our literature search to trials published in English or Chinese. Although a systematic review found that English-language restriction did not introduce a language bias, ${ }^{41}$ we conducted a comprehensive literature search including grey literature sources to minimize systematic bias.

Finally, the trials were not double-blinded because of the nature of the intervention and logistical problems. However, in 3 trials the investigators and statisticians were unaware of group allocation,,$^{19,33,35}$ and in 2 trials a predefined plan was

\section{A: HFNC v. conventional oxygen therapy}

\begin{tabular}{|c|c|c|c|}
\hline \multirow[b]{2}{*}{ Study } & \multicolumn{2}{|c|}{ Events, $n / N$} & \multirow[b]{2}{*}{ Risk ratio $(95 \% \mathrm{Cl})$} \\
\hline & HFNC & Control & \\
\hline \multicolumn{4}{|l|}{ Low risk } \\
\hline Frat et al. ${ }^{19}$ & $20 / 53$ & $44 / 94$ & 0.81 (0.54 to 1.21$)$ \\
\hline Hernandez et al. ${ }^{33}$ & $13 / 264$ & $32 / 263$ & 0.40 (0.22 to 0.75$)$ \\
\hline $\begin{array}{l}\text { Subtotal } \\
\text { Heterogeneity: } I^{2}=72 \%\end{array}$ & $33 / 317$ & $76 / 357$ & 0.59 (0.30 to 1.19$)$ \\
\hline \multicolumn{4}{|l|}{ High risk } \\
\hline Maggiore et al. ${ }^{21}$ & $6 / 53$ & $16 / 52$ & 0.37 (0.16 to 0.87$)$ \\
\hline $\begin{array}{l}\text { Subtotal } \\
\text { Heterogeneity: NA }\end{array}$ & $6 / 53$ & $16 / 52$ & 0.37 (0.16 to 0.87 ) \\
\hline Unknown risk & & & \\
\hline Perbet et al. ${ }^{34}$ & $9 / 40$ & $10 / 40$ & 0.90 (0.41 to 1.98$)$ \\
\hline $\begin{array}{l}\text { Subtotal } \\
\text { Heterogeneity: NA }\end{array}$ & $9 / 40$ & $10 / 40$ & 0.90 (0.41 to 1.98$)$ \\
\hline $\begin{array}{l}\text { Overall } \\
\text { Heterogeneity: } I^{2}=49 \%\end{array}$ & $48 / 410$ & $102 / 449$ & 0.60 (0.38 to 0.94$)$ \\
\hline
\end{tabular}

\section{B: HFNC v. noninvasive ventilation}

\begin{tabular}{|c|c|c|c|}
\hline \multicolumn{4}{|l|}{ Low risk } \\
\hline Frat et al. ${ }^{19}$ & $20 / 53$ & $55 / 110$ & 0.75 (0.51 to 1.12 \\
\hline Stephan et al. ${ }^{32}$ & $58 / 414$ & $57 / 416$ & 1.02 (0.73 to 1.44$)$ \\
\hline $\begin{array}{l}\text { Subtotal } \\
\text { Heterogeneity: } R^{2}=26 \%\end{array}$ & $78 / 467$ & $112 / 526$ & 0.89 ( 0.66 to 1.20 \\
\hline \multicolumn{4}{|l|}{ High risk } \\
\hline Simon et al. ${ }^{35}$ & $9 / 20$ & $13 / 20$ & 0.69 (0.39 to 1.24 \\
\hline $\begin{array}{l}\text { Subtotal } \\
\text { Heterogeneity: NA }\end{array}$ & $9 / 20$ & $13 / 20$ & 0.69 (0.39 to 1.24 \\
\hline $\begin{array}{l}\text { Overall } \\
\text { Heterogeneity: } l^{2}=2 \%\end{array}$ & $87 / 487$ & $125 / 546$ & 0.86 (0.68 to 1.09 \\
\hline
\end{tabular}
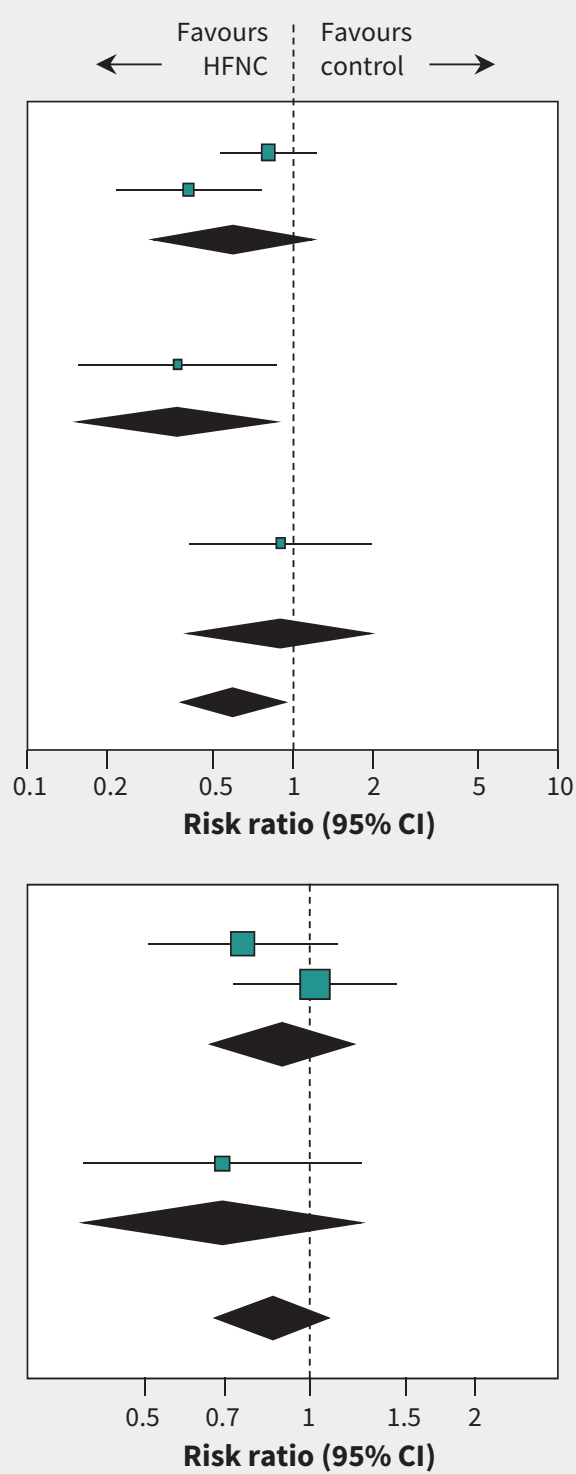

Figure 3: Subgroup analysis of intubation rate by disease severity for comparison of (A) high-flow nasal cannula (HFNC) oxygen therapy versus conventional oxygen therapy and (B) HFNC oxygen therapy versus noninvasive ventilation (NIV). Low risk = Acute Physiologic Assessment and Chronic Health Evaluation (APACHE) II score $<15$ or Simplified Acute Physiology Score (SAPS) II score $<30$. A risk ratio of less than 1.0 indicates an effect in favour of HFNC oxygen therapy. Error bars represent $95 \%$ confidence intervals. $\mathrm{Cl}=$ confidence interval, $\mathrm{NA}=$ not applicable. 
implemented to minimize bias. ${ }^{21,32}$ Therefore, the lack of double-blinding may not have influenced the primary outcome.

\section{Conclusion}

In patients with acute hypoxemic respiratory failure, HFNC oxygen therapy was associated with a reduction in the proportion requiring endotracheal intubation and a decreased respiratory rate compared with conventional oxygen therapy, but it had no effect on the $\mathrm{PaO}_{2}: \mathrm{FlO}_{2}$ ratio, $\mathrm{PaCO}_{2}$ level or arterial $\mathrm{pH}$. In the comparison of HFNC oxygen therapy and noninvasive ventilation, no differences were observed in the intubation rate, $\mathrm{PaCO}_{2}$ level or arterial $\mathrm{pH}$, but the respiratory rate was significantly lower in the HFNC group. In addition, our study showed that oxygenation was significantly better with noninvasive ventilation than with HFNC oxygen therapy; however, ICU mortality did not differ between groups. The correlation between oxygenation and ICU mortality should be re-evaluated.

Table 3: Pooled analysis of secondary outcome measures

\begin{tabular}{|c|c|c|c|c|c|}
\hline Outcome measure & $\begin{array}{c}\text { No. of } \\
\text { patients }\end{array}$ & $\begin{array}{l}\text { No. of } \\
\text { trials }\end{array}$ & $\begin{array}{c}\text { MD or RR } \\
(95 \% \mathrm{Cl})\end{array}$ & $I^{2}$ value, $\%$ & $\begin{array}{c}\text { Interaction } \\
p \text { value }\end{array}$ \\
\hline $\mathrm{PaO}_{2}: \mathrm{FlO}_{2}$ ratio, $\mathrm{mm} \mathrm{Hg}$ & & & & & $0.002^{\star}$ \\
\hline HFNC v. conventional oxygen therapy & 832 & 3 & $4.72(-28.90$ to 38.33$)$ & 90 & $<0.001 \dagger$ \\
\hline Low risk & & 2 & $-15.41(-42.68$ to 11.85$)$ & 87 & \\
\hline High risk & & 1 & $63.10(25.65$ to 100.55$)$ & & \\
\hline HFNC v. NIV & 1086 & 3 & $-53.84(-71.43$ to -36.24$)$ & 44 & $0.07 \dagger$ \\
\hline Low risk & & 2 & $-60.05(-72.75$ to -47.34$)$ & 0 & \\
\hline High risk & & 1 & $-21(-61.33$ to 19.33$)$ & & \\
\hline $\mathrm{PaCO}_{2}$ level, mm Hg & & & & & $0.9^{*}$ \\
\hline HFNC v. conventional oxygen therapy & 832 & 3 & $-0.40(-2.54$ to 1.74$)$ & 71 & $0.01 \dagger$ \\
\hline Low risk & & 2 & $0.69(-0.31$ to 1.69$)$ & 0 & \\
\hline High risk & & 1 & $-4.10(-2.54$ to 1.74$)$ & & \\
\hline HFNC v. NIV & 1086 & 3 & $-0.53(-2.34$ to 1.28$)$ & 62 & $0.3 \dagger$ \\
\hline Low risk & & 2 & $-0.18(-2.22$ to 1.86$)$ & 77 & \\
\hline High risk & & 1 & $-3.00(-7.66$ to 1.66$)$ & & \\
\hline Arterial pH & & & & & $0.8^{*}$ \\
\hline HFNC v. conventional oxygen therapy & 727 & 2 & $0.00(-0.03$ to 0.03$)$ & 37 & \\
\hline HFNC v. NIV & 1046 & 2 & $0.01(-0.00$ to 0.02$)$ & 24 & \\
\hline Respiratory rate, breaths/min & & & & & $0.1^{*}$ \\
\hline HFNC v. conventional oxygen therapy & 305 & 2 & $-3.68(-6.81$ to -0.55$)$ & 83 & \\
\hline HFNC v. NIV & 1046 & 2 & $-1.13(-2.01$ to -0.25$)$ & 8 & \\
\hline ICU mortality & & & & & $0.6^{\star}$ \\
\hline HFNC v. conventional oxygen therapy & 859 & 4 & 0.79 (0.44 to 1.40$)$ & 0 & $0.4 \dagger$ \\
\hline Low risk & & 3 & 0.68 (0.35 to 1.33$)$ & 0 & \\
\hline High risk & & 1 & 1.18 (0.38 to 3.62$)$ & & \\
\hline HFNC v. NIV & 993 & 2 & $0.79(0.31$ to 2.05$)$ & 74 & \\
\hline Length of ICU stay, d & & & & & $0.9^{*}$ \\
\hline HFNC v. conventional oxygen therapy & 832 & 3 & $0.02(-0.26$ to 0.30$)$ & 0 & $0.5 \dagger$ \\
\hline Low risk & & 2 & $0.01(-0.27$ to 0.29$)$ & 0 & \\
\hline High risk & & 1 & $1.30(-2.29$ to 4.89$)$ & & \\
\hline HFNC v. NIV & 1046 & 2 & $0.00(-0.20$ to 0.20$)$ & 0 & \\
\hline \multicolumn{6}{|l|}{ Pneumothorax rate } \\
\hline HFNC v. NIV & 830 & 1 & $1.15(0.42$ to 3.14$)$ & & \\
\hline
\end{tabular}




\section{References}

1. Esteban A, Frutos-Vivar F, Muriel A, et al. Evolution of mortality over time in patients receiving mechanical ventilation. Am J Respir Crit Care Med 2013; 188:220-30.

2. Grainge C. Breath of life: the evolution of oxygen therapy. J R Soc Med 2004; 97:489-93.

3. Ozsancak Ugurlu A, Sidhom SS, Khodabandeh A, et al. Use and outcomes of noninvasive positive pressure ventilation in acute care hospitals in Massachusetts. Chest 2014;145:964-71.

4. Burns KE, Meade MO, Premji A, et al. Noninvasive positive-pressure ventilation as a weaning strategy for intubated adults with respiratory failure. Cochrane Database Syst Rev 2013;(12):CD004127.

5. Peñuelas O, Frutos-Vivar F, Esteban A. Noninvasive positive-pressure ventilation in acute respiratory failure. CMAJ 2007;177:1211-8.

6. Keenan SP, Sinuff T, Burns KE, et al. Clinical practice guidelines for the use of noninvasive positive-pressure ventilation and noninvasive continuous positive airway pressure in the acute care setting. CMAJ 2011;183:E195-214.

7. Delclaux C, L'Her E, Alberti C, et al. Treatment of acute hypoxemic nonhypercapnic respiratory insufficiency with continuous positive airway pressure delivered by a face mask: a randomized controlled trial. JAMA 2000;284:2352-60.

8. Carrillo A, Gonzalez-Diaz G, Ferrer M, et al. Non-invasive ventilation in community-acquired pneumonia and severe acute respiratory failure. Intensive Care Med 2012;38:458-66.

9. Thille AW, Contou D, Fragnoli C, et al. Non-invasive ventilation for acute hypoxemic respiratory failure: intubation rate and risk factors. Crit Care 2013;17:R269.

10. Antonelli M, Conti G, Esquinas A, et al. A multiple-center survey on the use in clinical practice of noninvasive ventilation as a first-line intervention for acute respiratory distress syndrome. Crit Care Med 2007;35:18-25.

11. Demoule A, Girou E, Richard JC, et al. Benefits and risks of success or failure of noninvasive ventilation. Intensive Care Med 2006;32:1756-65.

12. Schettino G, Altobelli N, Kacmarek RM. Noninvasive positive-pressure ventilation in acute respiratory failure outside clinical trials: experience at the Massachusetts General Hospital. Crit Care Med 2008;36:441-7.

13. Nava S, Hill N. Non-invasive ventilation in acute respiratory failure. Lancet 2009;374:250-9.

14. Truwit JD, Bernard GR. Noninvasive ventilation - Don't push too hard. N Engl J Med 2004;350:2512-5.

15. Parke RL, Eccleston ML, McGuinness SP. The effects of flow on airway pressure during nasal high-flow oxygen therapy. Respir Care 2011;56:1151-5.

16. Parke R, McGuinness S, Dixon R, et al. Open-label, phase II study of routine high-flow nasal oxygen therapy in cardiac surgical patients. Br J Anaesth 2013;111:925-31.

17. Riera J, Pérez P, Cortés J, et al. Effect of high-flow nasal cannula and body position on end-expiratory lung volume: a cohort study using electrical impedance tomography. Respir Care 2013;58:589-96.

18. Rittayamai N, Tscheikuna J, Rujiwit P. High-flow nasal cannula versus conventional oxygen therapy after endotracheal extubation: a randomized crossover physiologic study. Respir Care 2014;59:485-90.

19. Frat JP, Thille AW, Mercat A, et al.; FLORALI Study Group; REVA Network. High-flow oxygen through nasal cannula in acute hypoxemic respiratory failure. $N$ Engl J Med 2015;372:2185-96.

20. Roca O, Riera J, Torres F, et al. High-flow oxygen therapy in acute respiratory failure. Respir Care 2010;55:408-13.

21. Maggiore SM, Idone FA, Vaschetto R, et al. Nasal high-flow versus Venturi mask oxygen therapy after extubation. Effects on oxygenation, comfort, and clinical outcome. Am J Respir Crit Care Med 2014;190:282-8.
22. Sotello D, Rivas M, Mulkey Z, et al. High-flow nasal cannula oxygen in adult patients: a narrative review. Am J Med Sci 2015;349:179-85.

23. Kernick J, Magarey J. What is the evidence for the use of high flow nasal cannula oxygen in adult patients admitted to critical care units? A systematic review. Aust Crit Care 2010;23:53-70.

24. Jones T, Evans D. Conducting a systematic review. Aust Crit Care 2000;13:66-71.

25. Higgins J, Green S, eds. Cochrane handbook for systematic reviews of interventions. Version 5.1.0 [updated March 2011]. Oxford (UK): The Cochrane Collaboration; 2011. Available: www.handbook.cochrane.org (accessed 2016 Dec. 6).

26. Moher D, Liberati A, Tetzlaff J, et al. Preferred reporting items for systematic reviews and meta-analyses: the PRISMA statement. BMJ 2009;339:b2535.

27. Higgins JP, Altman DG, Gøtzsche PC, et al. The Cochrane Collaboration's tool for assessing risk of bias in randomised trials. BMJ 2011;343:d5928.

28. Chalmers TC, Celano P, Sacks HS, et al. Bias in treatment assignment in controlled clinical trials. N Engl J Med 1983;309:1358-61.

29. Schulz KF, Chalmers I, Hayes RJ, et al. Empirical evidence of bias. Dimensions of methodological quality associated with estimates of treatment effects in controlled trials. JAMA 1995;273:408-12.

30. Higgins JP, Thompson SG, Deeks JJ, et al. Measuring inconsistency in metaanalyses. BMJ 2003;327:557-60.

31. Higgins JP, Thompson SG. Quantifying heterogeneity in a meta-analysis. Stat Med 2002;21:1539-58.

32. Stéphan F, Barrucand B, Petit P, et al. High-flow nasal oxygen vs noninvasive positive airway pressure in hypoxemic patients after cardiothoracic surgery: a randomized clinical trial. JAMA 2015;313:2331-9.

33. Hernández G, Vaquero C, González P, et al. Effect of postextubation high-flow nasal cannula vs conventional oxygen therapy on reintubation in low-risk patients: a randomized clinical trial. JAMA 2016;315:1354-61.

34. Perbet S, Gerst A, Chabanne R, et al. High-flow nasal oxygen cannula versus conventional oxygen therapy to prevent postextubation lung aeration loss: a multicentric randomized control lung ultrasound study [oral session 0446]. Abstracts ESICM LIVES 2014 27th Annual Congress, Barcelona, Spain. Intensive Care Med 2014;40(Suppl 1):S128.

35. Simon M, Braune S, Frings D, et al. High-flow nasal cannula oxygen versus noninvasive ventilation in patients with acute hypoxaemic respiratory failure undergoing flexible bronchoscopy - a prospective randomised trial. Crit Care 2014;18:712.

36. Sztrymf B, Messika J, Bertrand F, et al. Beneficial effects of humidified high flow nasal oxygen in critical care patients: a prospective pilot study. Intensive Care Med 2011;37:1780-6.

37. Messika J, Ahmed KB, Gaudry S, et al. Use of high-flow nasal cannula oxygen therapy in subjects with ARDS: a 1-year observational study. Respir Care 2015;60:162-9.

38. Schwabbauer N, Berg B, Blumenstock G, et al. Nasal high-flow oxygen therapy in patients with hypoxic respiratory failure: effect on functional and subjective respiratory parameters compared to conventional oxygen therapy and noninvasive ventilation (NIV). BMC Anesthesiol 2014;14:66.

39. Parke R, McGuinness S, Eccleston M. Nasal high-flow therapy delivers low level positive airway pressure. Br J Anaesth 2009;103:886-90.

40. Mündel T, Feng S, Tatkov S, et al. Mechanisms of nasal high flow on ventilation during wakefulness and sleep. J Appl Physiol (1985) 2013;114:1058-65.

41. Morrison A, Polisena J, Husereau D, et al. The effect of English-language restriction on systematic review-based meta-analyses: a systematic review of empirical studies. Int J Technol Assess Health Care 2012;28:138-44.

\section{Competing interests: None declared.}

This article has been peer reviewed.

Affiliations: Department of Anesthesiology and Translational Neuroscience Center (Ou, Liu, Gong, Zhao), Laboratory of Anesthesia and Critical Care Medicine, West China Hospital of Sichuan University, Chengdu, Sichuan; Department of Anesthesiology (Hua), Subei People's Hospital of Jiangsu Province, Clinical Medical College, Yangzhou University, Yangzhou, Jiangsu, China
Contributors: Xiaofeng Ou and Yusi Hua contributed substantially to the study concept and design, the literature screening, the acquisition of data, and the analysis and interpretation of data. Cansheng Gong and Wenling Zhao provided arbitration in cases of disagreement, literature screening, data extraction and interpretation. Jin Liu oversaw the project. Xiaofeng Ou drafted the manuscript. Yusi Hua, Cansheng Gong, Wenling Zhao and Jin Liu provided critical feedback on the manuscript. All of the authors revised it for important intellectual content, approved the final version to be published and agreed to act as guarantors of the work.

Accepted: Aug. 28, 2016

Correspondence to: Jin Liu, 2014324020096@stu.scu.edu.cn 